\title{
Effects of Thermal and Electrical Stressing on the Breakdown Behavior of Space Wiring
}

Ahmad Hammoud and Mark Stavnes

NYMA, Inc.

Brook Park, Ohio

Jayant Suthar and Javaid Laghari

State University of New York at Buffalo

Buffalo, New York

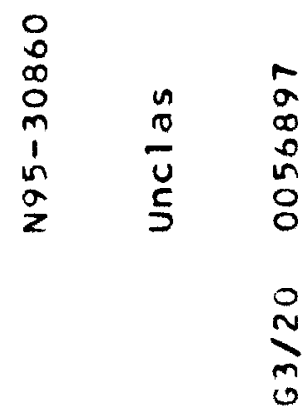

June 1995

z

Z出

Prepared for

Lewis Research Center

Under Contract NAS3-27186

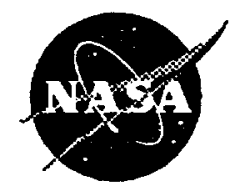

National Aeronautics and

Space Administration 


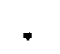




\section{EFFECTS OF THERMAL AND ELECTRICAL STRESSING ON THE BREAKDOWN BEHAVIOR OF SPACE WIRING}

\author{
Ahmad Hammoud \& Mark Stavnes \\ NYMA, Inc. \\ NASA Lewis Research Center \\ Cleveland, Ohio 44135
}

\author{
Jayant Suthar \& Javaid Laghari \\ SUNY at Buffalo \\ ECE Department \\ Buffalo, New York 14250
}

\begin{abstract}
Several failures in the electrical wiring systems of many aircraft and space vehicles have been attributed to arc tracking and damaged insulation. In some instances, these failures proved to be very costly as they have led to the loss of many aircraft and imperilment of space missions. Efforts are currently underway to develop lightweight, reliable, and arc track resistant wiring for aerospace applications. In this work, six wiring constructions were evaluated in terms of their breakdown behavior as a function of temperature. These hybrid constructions employed insulation consisting of Kapton, Teflon, and cross-linked Tefzel. The properties investigated included the $400 \mathrm{~Hz}$ AC dielectric strength at ambient and $200^{\circ} \mathrm{C}$, and the lifetime at high temperature with an applied bias of 40 , 60 , and $80 \%$ of breakdown voltage level. The results obtained are discussed, and conclusions are made concerning the suitability of the wiring constructions investigated for aerospace applications.
\end{abstract}

\section{Introduction}

Failures in aerospace vehicles have been reported both on the ground and in-flight due to persistent arcs in the wiring harnesses. The arc typically propagates along the wire and causes the loss of the entire wire harness along with all associated functions. Such failure mechanisms, which are not accounted for in the present engineering design practices, represent a serious problem for advanced aerospace vehicles. The effects of insulation failure can be very costly in terms of loss of expensive equipment, imperilment of missions, and loss of lives.

Since the mid sixties, MIL-W-81381 polyimide (Kapton)-insulated wire has been the material of choice for most aerospace applications due to its high dielectric strength, excellent thermal properties, non-flammability, low weight, and high abrasion resistance [1]. However, wiring system failures became unexpectedly common in a number of applications. The failures result when damage, cracking, or deterioration of the insulation occur due to exposure to water or certain other liquids, or when the material is subject to mechanical stresses, such as sharp bending. One of the failure mechanisms which has been recently identified is arc tracking. This phenomenon results when the insulation becomes conductive upon arc initiation. Specific instances have involved wiring systems using polyimide type of insulation. Insulation degradation, such as chafing or cracking, can result in electrical arcing from a live wire through the insulation to ground or to an adjacent wire with different potential. The heat caused by the arc results in pyrolysis of the polyimide film [2]. The pyrolized film forms a conductive path of carbon residue, allowing the arc to propagate along the wire bundle resulting in the loss of an entire wiring harness. Therefore, it has become essential to identify or develop wiring systems that are arc track resistant, reliable, and suitable for aerospace applications.

The present work evaluates the dielectric strength of six cable insulation systems. The insulation utilized in these systems consisted of Kapton, Teflon, and crosslinked Tefzel. The breakdown behavior and time-tobreakdown were obtained at high temperatures. Presented in this paper are the results which were obtained along with a general assessment of the various constructions.

\section{Experimental Procedure}

The present work evaluates the dielectric strength of six wiring constructions. These include MLL-W-81381/7, Thermatics, Filotex, Tensolite, MIL-W-22759/12, and MIL-W-22759/34. These AWG 20 (American Wire Gauge 20) wiring constructions had insulation comprised of different combinations of Kapton (PI), Teflon (PTFE), and cross-linked Tefzel (XI-ETFE). Detailed descriptions of these constructions are given in Table 1. Breakdown measurements were performed on these wiring constructions under a $400 \mathrm{~Hz}$ electric field (relevant to aerospace applications) at $23^{\circ} \mathrm{C}$ and $200^{\circ} \mathrm{C}$ in a circulating hot air environment. Each wiring specimen was about twelve inches long. The entire surface of the sample was cleaned with heptane to minimize contamination of the surface due to handling. A ten minute time interval was allowed for each sample to reach the proper test temperature. 
Table 1. Wiring Construction Systems

\begin{tabular}{l|c|c}
\hline \multicolumn{1}{c|}{ Sample } & $\begin{array}{c}\text { Insulation } \\
\text { System }\end{array}$ & $\begin{array}{c}\text { Insulation } \\
\text { Thickness (mil) }\end{array}$ \\
\hline MIL-W-81381/7 & PI/PI & 6.0 \\
MIL-W-22759/12 & PTFE & 6.0 \\
MIL-W-22759/34 & XI-ETFE/XL-ETFE & 6.0 \\
Thermatics & PTFE/PI/PTFE & 6.0 \\
Filotex & PTFE/PI/FEP & 6.5 \\
Tensolite & PTFE/PI/PTFE & 6.1 \\
\hline
\end{tabular}

High voltage was applied to the wiring conductor, which was looped between two grounded electrodes (round edge parallel plates). Until breakdown occurred, the voltage was raised at a rate of $500 \mathrm{~V} / \mathrm{sec}$ (complying with ASTM D149). Due to the statistical nature of the experiment, seven replicate measurements were obtained for each breakdown voltage data point reported.

In addition to their breakdown behavior, the wiring constructions were also evaluated in terms of their lifetime (time-to-breakdown) at a temperature of $200^{\circ} \mathrm{C}$. Each sample was characterized at an applied bias of 40 , 60 , and $80 \%$ of its corresponding breakdown voltage level obtained at $200^{\circ} \mathrm{C}$.

\section{Results and Discussion}

The breakdown voltages of the wiring constructions under $400 \mathrm{~Hz}$ at $23^{\circ} \mathrm{C}$ and $200^{\circ} \mathrm{C}$ are shown in Table 2. It can be seen that while MII-W-22759/34 displays the highest breakdown strength at $23^{\circ} \mathrm{C}$, it is outperformed by MIL-W- $81381 / 7$ at $200^{\circ} \mathrm{C}$. At both temperatures, the Filotex sample exhibits the lowest breakdown strength of all samples tested. It is also apparent from the table that all systems, regardless of the insulation type and structure, undergo a slight to moderate decrease in their breakdown voltages at $200^{\circ} \mathrm{C}$ from their room temperature values. The reduction in the breakdown strength can be attributed to the softening and degradation of the polymer at high temperatures [3], and to an increase in the dielectric loss [4].

The results of the $400 \mathrm{~Hz}$ aging test at $200^{\circ} \mathrm{C}$ are shown in Figures 1 - 6 for all wiring insulation systems tested at applied electrical stresses of $40 \%, 60 \%$, and $80 \%$ of the dielectric strength. A clear reduction in the breakdown time is noticeable, for all samples, as the applied electrical stress is increased. MIL-W-81381/7 clearly exhibited the longest breakdown times (aging life) of all the wiring tested, while Filotex had the shortest life at any given stress.

Figure 7 shows a comparison of the results of the voltage-time characteristics of all the wiring constructions. It can clearly be seen from this figure that MIL-W-81381 shows the best performance (i.e. longest life for any applied electrical stress), as

Table 2. Dielectric Strength of Wiring Insulation Systems

\begin{tabular}{l|c|c}
\hline \multicolumn{1}{c|}{$\begin{array}{c}\text { Insulation } \\
\text { System }\end{array}$} & $23^{\circ} \mathrm{C} \mathrm{kV}_{(0-\mathrm{p})}$ & $200^{\circ} \mathrm{C} \mathrm{kV}_{(0-\mathrm{p})}$ \\
\hline MIL-W-81381/7 & 25.7 & 22.5 \\
MIL-W-22759/12 & 14.2 & 12.3 \\
MIL-W-22759/34 & 28.9 & 20.7 \\
Thermatics & 14.3 & 12.2 \\
Filotex & 10.2 & 6.7 \\
Tensolite & 14.2 & 14.0 \\
\hline
\end{tabular}


compared to all other wiring insulation systems tested. Again, the Filotex construction shows the worst performance within the range tested.

The reduction in the time-to-breakdown of the cable insulation with increase in the applied electrical stress can be attributed to many factors. Possibly, when the applied voltage is increased, energy stored in the sample and losses due to the dissipation factor (dielectric loss) are generated and subsequently converted into heat. This heat raises the sample temperature which can not be dissipated outside due to the higher surrounding temperature. Consequently, at one instant, the so-called critical temperature is reached, causing the leakage current to increase rapidly which leads to the breakdown of the sample [5].

\section{Conclusion}

NASA's requirements in future manned and unmanned space activities will place increasing demands on electrical wiring and thus increase the likelihood of arcinduced failures. The wiring insulations for future missions must therefore be reliable and, in particular, resistant to arc tracking. Amongst the wiring constructions tested in this work, MIL-W-81381 shows the highest breakdown voltage and the longest time-tobreakdown at $200^{\circ} \mathrm{C}$ and applied electric field of 400 Hz. MIL-W-22759/34 construction exhibits similar results. Despite their lower breakdown voltage, the other four candidates display good stability with thermal aging and electrical stressing. Further testing is required on the candidate constructions to address the NASA unique operational requirements in order to establish reliability and suitability of these wiring systems for use in aerospace applications. These tests include, but are not limited to, outgassing, flammability, and arc tracking phenomena under high temperature, low pressure, and microgravity conditions.

\section{Acknowledgement}

This work was supported by NASA Lewis Research Center, Cleveland, Ohio under Contract \#NAS3-27186 and Grant \#NAG-31345.

\section{References}

[1] J.L. Christian, J.E. Dickman, R.W. Bercaw, I.T. Myers, A.N. Hammoud, M.W. Stavnes and J. Evans, "Wiring for Aerospace Applications," 1992 Power Electronics Specialists Conference, Toledo, Spain, June 1992.

[2] M.W. Stavnes and A.N. Hammoud, "NASA Requirements and Application Environments for Electrical Power Wiring," NASA CR-191064, August 1992.

[3] A.N. Hammoud, E.D. Baumann, E. Overton, I.T. Myers, J.L. Suthar, J.R. Laghari, and W. Khachen, "High Temperature Dielectric Properties of APICAL, Kapton, Teflon AF, and UPILEX Polymers," Conference on Electrical Insulation and Dielectric Phenomena, British Columbia, Canada, October 1992.

[4] J.L. Suthar and J.R. Laghari, "Breakdown Studies of Teflon Perfluoroalkoxy Film at High Temperature," Journal of Materials Science, Vol. $27,1992$.

[5] J.J. O'Dwyer, The Theory of Electrical Conduction and Breakdown in Solid Dielectrics, Oxford University Press, London, 1973.

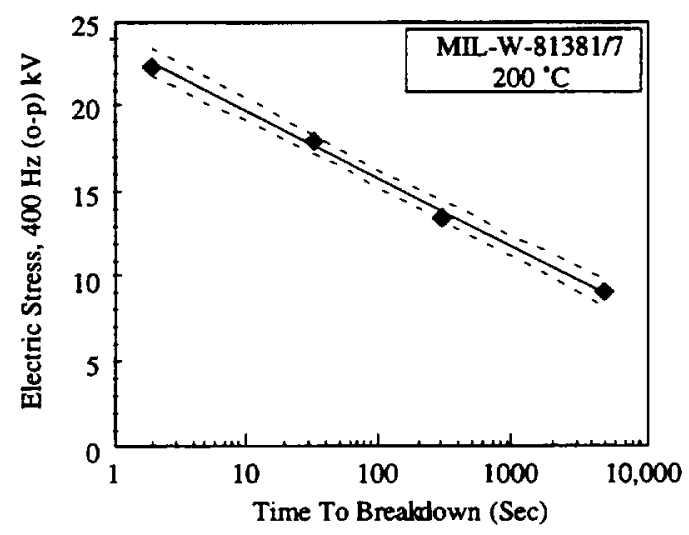

Figure 1. Voltage-Time Relationship of MIL-W-81381/7 at $200^{\circ} \mathrm{C}$ and Various Electrical Stresses. 


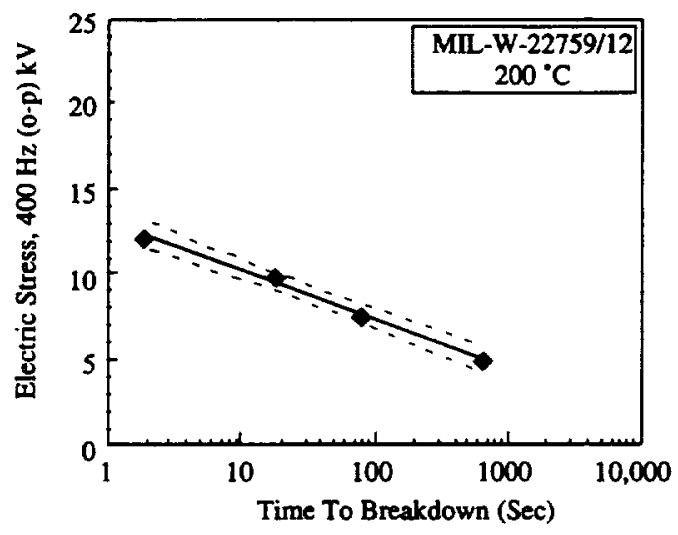

Figure 2. Voltage-Time Relationship of MIL-W-22759/12 at $200^{\circ} \mathrm{C}$ and Various Electrical Stresses.

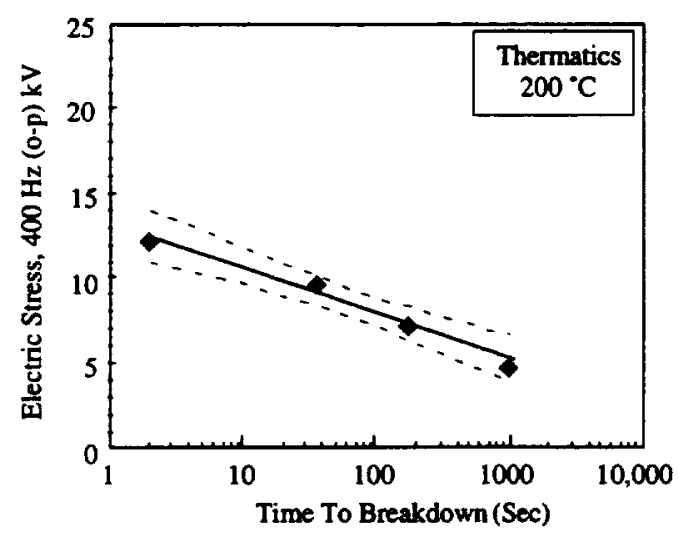

Figure 4. Voltage-Time Relationship of Thermatics at $200^{\circ} \mathrm{C}$ and Various Electrical Stresses.

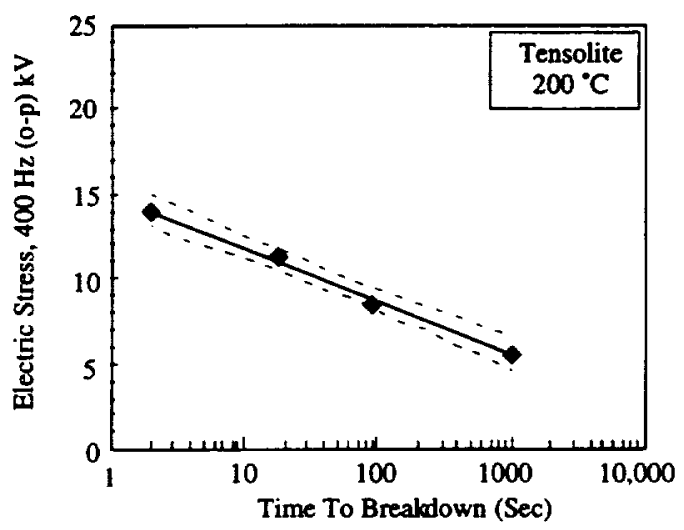

Figure 6. Voltage-Time Relationship of Tensolite at $200^{\circ} \mathrm{C}$ and Various Electrical Stresses.

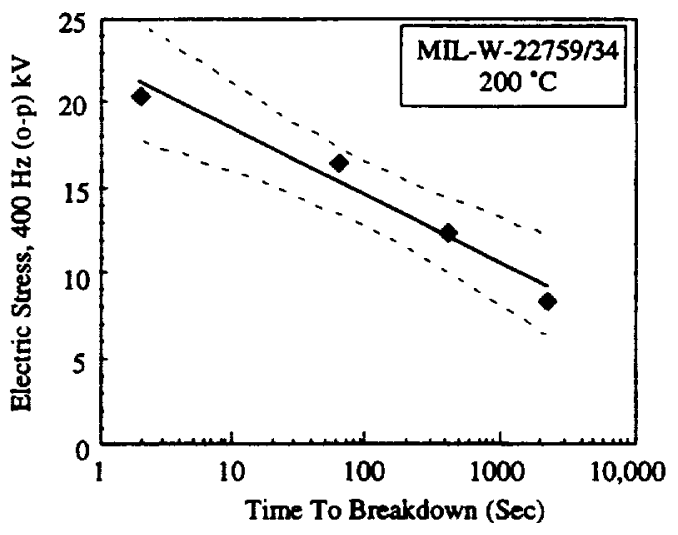

Figure 3. Voltage-Time Relationship of MII-W-22759/34 at $200^{\circ} \mathrm{C}$ and Various Electrical Stresses.

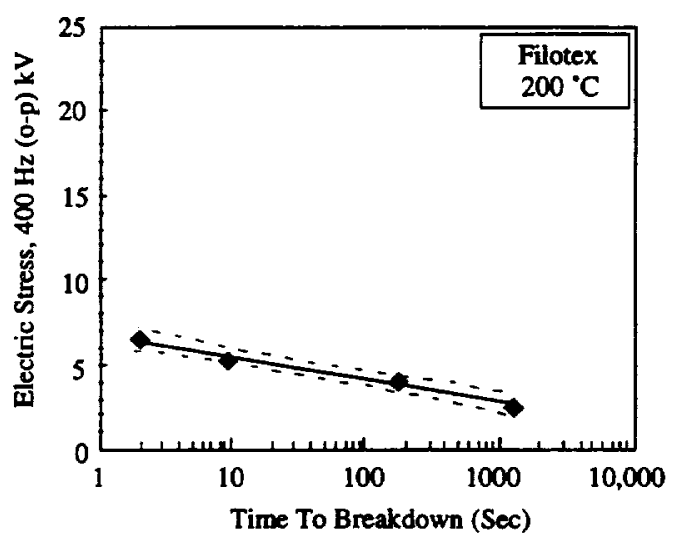

Figure 5. Voltage-Time Relationship of Filotex at $200^{\circ} \mathrm{C}$ and Various Electrical Stresses.

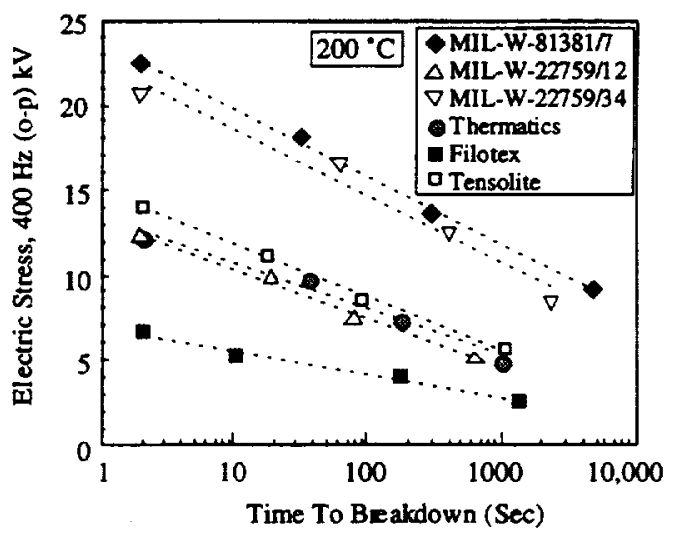

Figure 7. Time-To-Breakdown Characteristics of Wiring Constructions at $200^{\circ} \mathrm{C}$ and Various Electrical Stresses. 


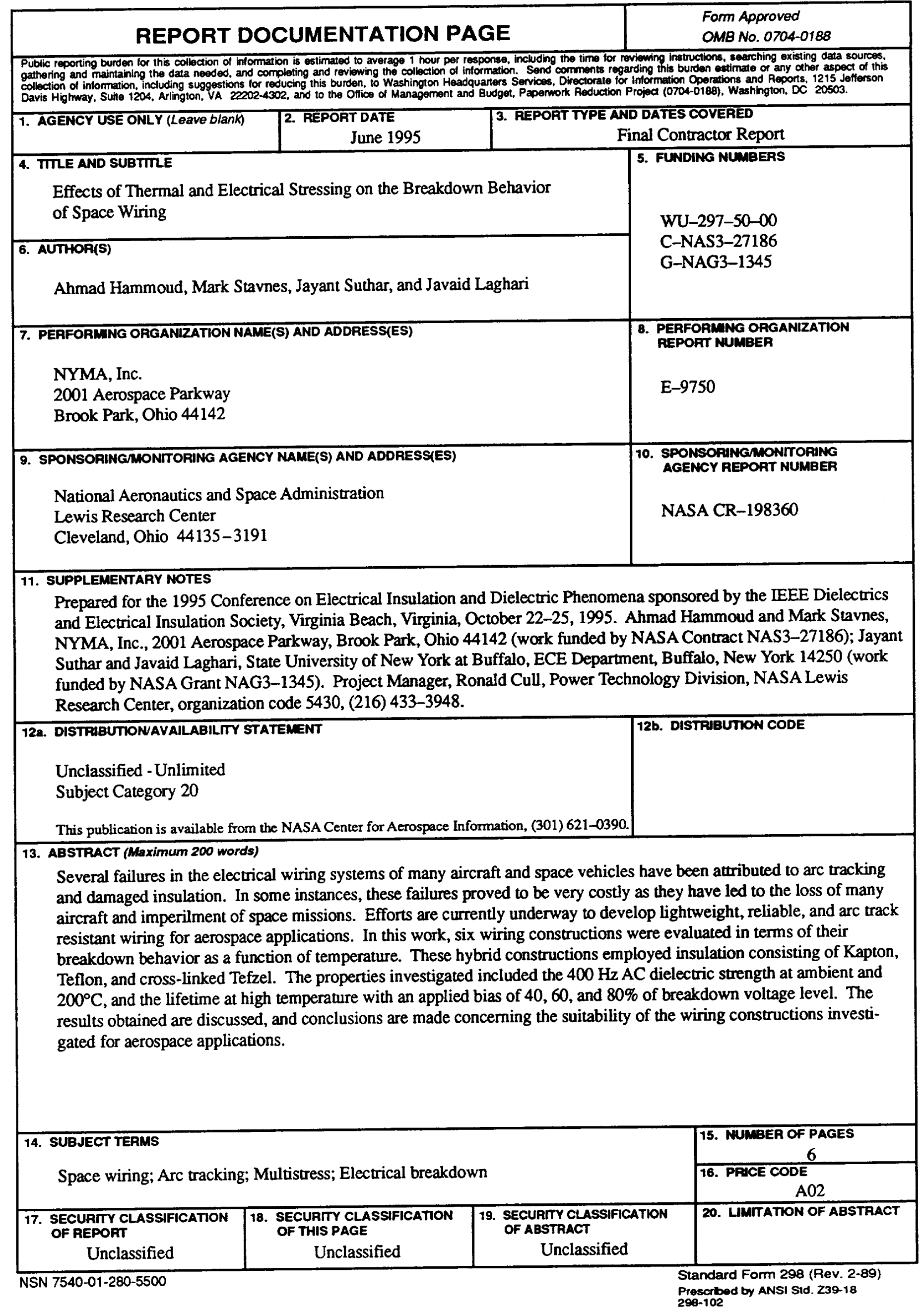


